\title{
KINERJA PIPA KALOR DENGAN STRUKTUR SUMBU FIBER CARBON dan STAINLESS STEEL MESH 100 dengan FLUIDA KERJA AIR
}

\author{
I Wayan Sugita \\ Program Studi Teknik Mesin, Fakultas Teknik, Universitas Negeri Jakarta \\ e-mail : wayan-su@ unj.ac.id
}

\begin{abstract}
ABSTRAK
Penelitian ini bertujuan untuk mengetahui kinerja pipa kalor dengan struktur sumbu fiber carbon yang akan dibandingkan terhadap pipa kalor dengan struktur sumbu stainless steel mesh 100. Dilakukan perhitungan kinerja pipa kalor pada berbagai variasi sudut pengoperasian $\left(0^{\circ}-90^{\circ}\right)$, dengan menghitung laju perpindahan panas dan koefisien perpindahan panas konduksi. Metode yang digunakan dalam penelitian ini adalah metode eksperimen. Pipa kalor yang menggunakan struktur sumbu fiber carbon dan struktur sumbu stainless steel mesh 100 dibuat dari bahan pipa tembaga dengan diameter luar $9.525 \mathrm{~mm}$, tebal $0.8 \mathrm{~mm}$, panjang $300 \mathrm{~mm}$. Didalam pipa kalor dimasukkan struktur sumbu fiber carbon dan stainless steel mesh 100. Fluida kerja yang digunakan adalah air karena air mudah didapat serta memenuhi syarat utama sebagai fluida kerja, yaitu tidak bereaksi dengan material pipa maupun struktur sumbu (wick), mampu beroperasi pada temperatur $30^{\circ}$ $200^{\circ} \mathrm{C}$, sifat termalnya stabil dan panas laten yang tinggi. Pengujian pipa kalor dengan memberikan beban panas pada evaporator sebesar $14 \mathrm{~W}$ dan mendinginkannya pada bagian kondensor dengan pendinginan dilakukan secara konveksi paksa menggunakan air pada debit yang konstan.

Hasil yang didapat menunjukkan bahwa laju perpindahan panas dan koefisien perpindahan panas konduksi pipa kalor dengan struktur sumbu fiber carbon dalam berbagai variasi sudut selalu lebih besar dibandingkan dengan pipa kalor struktur sumbu stainless steel mesh 100. Laju perpindahan panas tertinggi terjadi pada pipa kalor struktur sumbu fiber carbon dengan sudut $90^{\circ}$ sebesar $13.8 \mathrm{~W}$. Koefisien perpindahan panas konduksi pipa kalor struktur sumbu fiber carbon lebih besar dibandingkan dengan pipa kalor struktur sumbu stainless steel mesh 100 dengan nilai terbesar 16299.96 yang terjadi pada sudut $90^{\circ}$.
\end{abstract}


Kata Kunci : Pipa Kalor, Struktur Sumbu, Fluida Kerja PENDAHULUAN

Pipa kalor adalah perangkat yang dapat memindahkan panas dari suatu titik ke titik yang lain dengan sangat cepat pada beda temperatur kecil, konstan dan dengan kapasitas perpindahan panas yang besar [1]. Pipa kalor merupakan perangkat yang sederhana, murah dalam pembuatan dan perawatannya. Pipa kalor pertamakali diperkenalkan oleh R.s Gaugler pada tahun 1942. Cikal bakal terbentuknya pipa kalor berasal dari pipa perkins pada abad 18, saat ini dikenal sebagai pipa thermosyphon. Kemudian R.s Gaugler dari General Motors, ohio, USA mengembangkan pipa thermosyphon dengan menambahkan struktur sumbu didalam pipa dengan tujuan untuk mempercepat laju aliran fluida cair. Pipa tersebut dipatenkan dengan nama pipa kalor, kemudian dikembangkan lagi oleh G.M Grover pada tahun 1964 dari laboratorium Los Alamos Nasional, New Mexico yang mempublikasikan artikel pertama tentang pipa kalor [2].

Pipa kalor terdiri atas pipa berongga yang kedua ujungnya tertutup yang didalamnya terdapat fluida kerja dan struktur sumbu (wick) seperti ditunjukkan oleh gambar 1. Daerah pipa kalor secara aksial dibagi menjadi tiga bagian yaitu evaporator, adiabatik dan kondensor. Pipa berfungsi sebagai wadah untuk mengisolasi fluida kerja, tempat struktur sumbu dan tempat untuk terjadinya proses perpindahan panas. Fluida kerja berfungsi untuk memindahkan panas dari evaporator ke kondensor. Struktur sumbu (wick) berfungsi sebagai media yang dilalui fluida kerja dalam fasa cair untuk kembali ke evaporator dari kondensor dan menjaga distribusi cairan merata pada dinding pipa. 


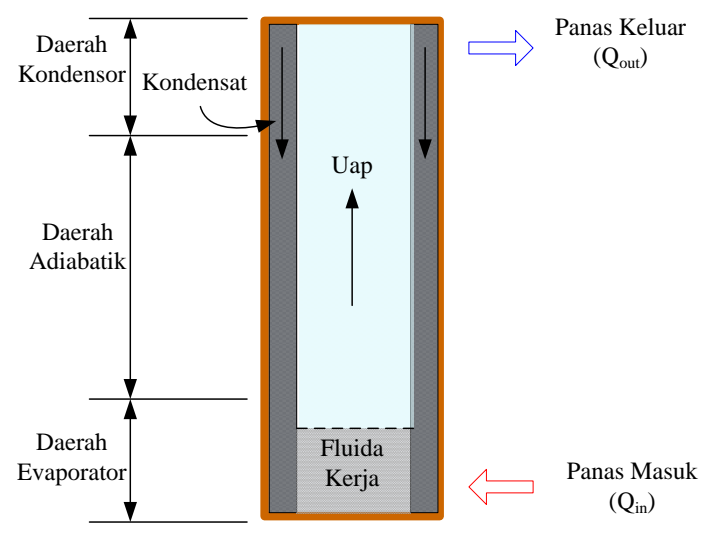

Gambar 1 Struktur Pipa Kalor

Prinsip kerja dari pipa kalor adalah panas masuk pipa kalor melalui bagian evaporator, merambat melewati dinding pipa secara radial kemudian memanasi dan menyebabkan fluida kerja yang ada di dalam pipa menguap. Uap yang terbentuk mengalir ke ujung kondensor dari pipa kalor melalui rongga uap. Sampai di kondensor panas dari uap ini diambil oleh pendingin melalui dinding pipa sehingga uap ini terkondensasi, kondensat yang terbentuk pada dinding pipa dan permukaan struktur sumbu mengalir kembali ke evaporator melalui struktur sumbu dengan efek kapilaritas, atau gaya gravitasi [1] [3]. Sirkulasi fluida kerja terjadi secara terus menerus selama pipa kalor beroperasi dengan normal. Proses ini akan berlangsung secara terus menerus sepanjang adanya panas yang diterima dibagian evaporator. Karena mekanisme perpindahan panas pada pipa kalor berdasarkan pada panas laten maka konduktivitas panas pipa kalor ratusan kali lebih tinggi dibandingkan dengan konduktivitas panas dari pipa tembaga biasa.

\section{PIPA KALOR dan PROSEDUR PENELITIAN}

\section{Pipa Kalor}

Pipa kalor dibuat dari pipa tembaga dengan ukuran panjang $300 \mathrm{~mm}$, diameter luar $10 \mathrm{~mm}$. Panjang evaporator $50 \mathrm{~mm}$ dan panjang kondensor $50 \mathrm{~mm}$, ditunjukkan oleh gambar 2 .

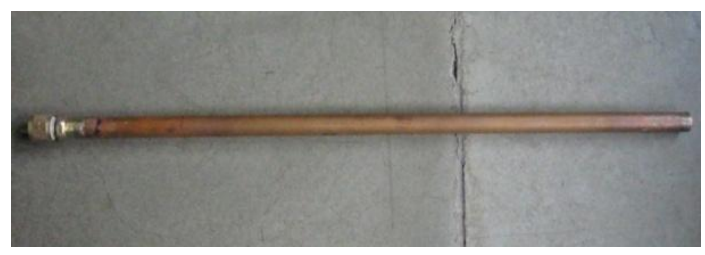




\section{Gambar 2 Rancangan Pipa Kalor}

Struktur sumbu yang akan digunakan adalah struktur sumbu fiber carbon dan struktur sumbu anyaman (wire mesh screen) dengan bahan stainless stell AISI 304 angka mesh sebesar 100 yang ditunjukkan oleh gambar 3.

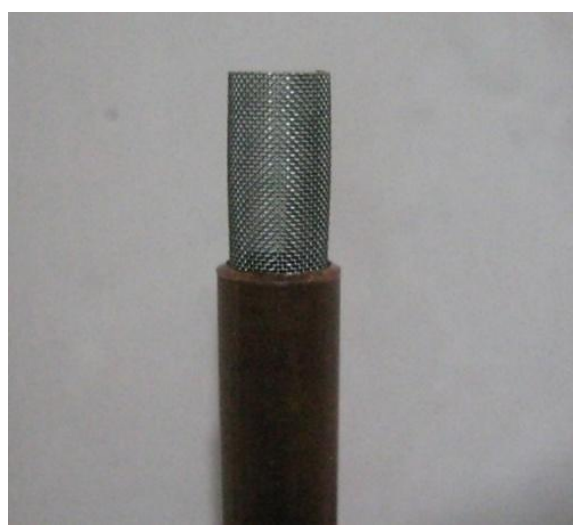

Gambar 3 Pipa Tembaga dengan Wick

Fluida kerja yang digunakan adalah air dengan filling ratio $10 \%$. Pada bagian evaporator dipasang elemen pemanas untuk memanaskan pipa kalor dengan daya $14 \mathrm{~W}$.

Pada bagian kondensor dipasangkan selubung pipa kaca untuk mengalirkan air pendingin, dengan laju konstan sebesar $6 \times 10^{-4} \mathrm{~kg} / \mathrm{s}$.

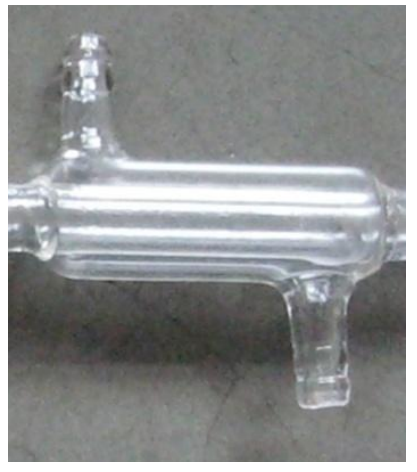

Gambar 4 Kondensor

Temperatur diukur menggunakan termokopel yang dilekatkan pada pipa dengan posisi diukur dari ujung evaporator, yaitu $25 \mathrm{~mm}$ (evaporator, $\mathrm{T}_{\mathrm{e}}$ ), $150 \mathrm{~mm}$ (adiabatic, $\mathrm{T}_{\mathrm{a}}$ ) dan $295 \mathrm{~mm}$ (kondensor, $\mathrm{T}_{\mathrm{c}}$ ), juga pada air pendingin yang masuk $\left(\mathrm{T}_{\mathrm{in}}\right)$ dan keluar selubung kondenser $\left(\mathrm{T}_{\text {out }}\right)$ seperti ditunjukkan oleh gambar 5 . 


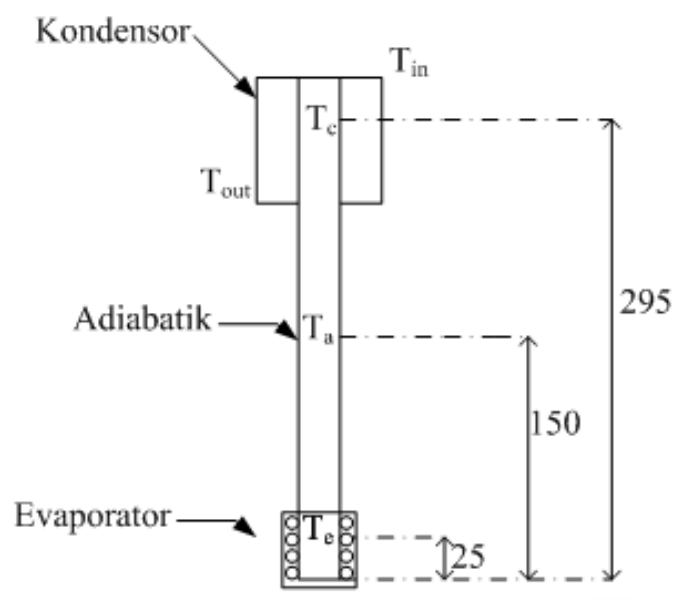

Gambar 5 Pemasangan termokopel pada pipa kalor (mm)

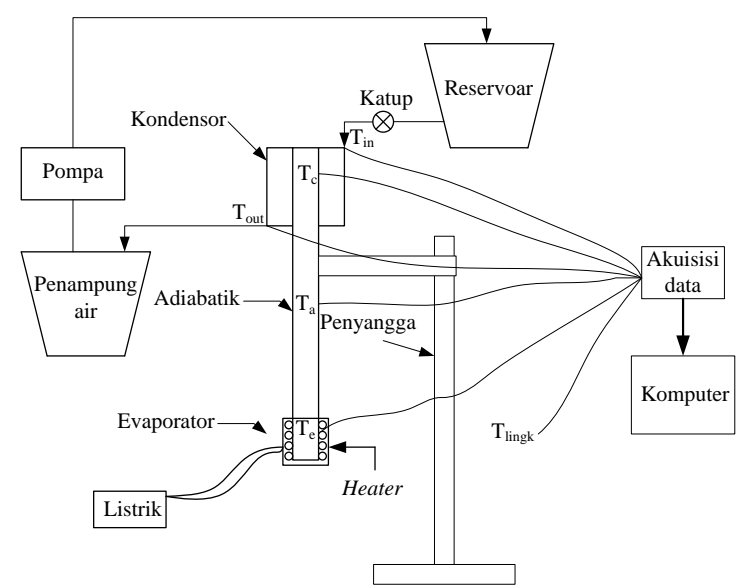

Gambar 6 Rancangan Penelitian

\section{Prosedur Penelitian}

Bagian evaporator pipa kalor dipanaskan dengan mengaliri listrik pada elemen pemanas sebesar 14W. Bagian kondensor pipa kalor dilairi air pendingin secara konstan untuk membuang panas dari pipa kalor, kemudian data temperature dicatat. Data temperatur yang akan diambil adalah temperatur kondensor $\left(\mathrm{T}_{\mathrm{c}}\right)$, evaporator, $\left(\mathrm{T}_{\mathrm{e}}\right)$, pendingin masuk $\left(\mathrm{T}_{\mathrm{in}}\right)$ pendingin keluar $\left(\mathrm{T}_{\text {out }}\right)$ dengan posisi sudut posisi pipa kalor dari $0^{\circ}, 30^{\circ}, 45^{\circ}, 60^{\circ}$ dan $90^{\circ}$.

\section{HASIL dan ANALISA}

Dari penelitian yang dilakukan diperoleh hasil sebagai berikut : 
Tabel 1 Variasi perubahan temperatur pipa kalor terhadap sudut kemiringan

\begin{tabular}{|c|c|c|c|c|c|c|c|c|}
\hline \multirow{2}{*}{ Sudut } & \multicolumn{4}{|c|}{ Sumbu fiber Carbon } & \multicolumn{4}{|c|}{ Sumbu stainless stell mesh 100} \\
\hline & $\begin{array}{l}\mathrm{T}_{\mathrm{e}} \\
\left({ }^{\mathrm{o}} \mathrm{C}\right)\end{array}$ & $\begin{array}{l}\mathbf{T}_{\mathbf{c}} \\
\left({ }^{\circ} \mathbf{C}\right)\end{array}$ & $\begin{array}{l}\mathbf{T}_{\text {in }} \\
\left({ }^{\circ} \mathbf{C}\right)\end{array}$ & $\begin{array}{l}\mathrm{T}_{\text {out }} \\
\left({ }^{\circ} \mathrm{C}\right)\end{array}$ & $\begin{array}{l}\mathbf{T}_{\mathbf{e}} \\
\left({ }^{\circ} \mathbf{C}\right)\end{array}$ & $\begin{array}{l}\mathbf{T}_{\mathbf{c}} \\
\left({ }^{\circ} \mathbf{C}\right)\end{array}$ & $\begin{array}{l}\mathbf{T}_{\mathrm{in}} \\
\left({ }^{\circ} \mathrm{C}\right)\end{array}$ & $\begin{array}{l}\mathrm{T}_{\text {out }} \\
\left({ }^{\circ} \mathrm{C}\right)\end{array}$ \\
\hline 0 & 65.99 & 61.05 & 28.66 & 33.91 & 84.95 & 79.45 & 30.77 & 35.65 \\
\hline 30 & 64.99 & 60.99 & 28.49 & 33.81 & 83.55 & 78.55 & 30.72 & 35.79 \\
\hline 45 & 62.97 & 59.46 & 27.65 & 33.00 & 81.54 & 77.14 & 30.57 & 35.75 \\
\hline 60 & 62.87 & 59.56 & 26.72 & 32.11 & 81.41 & 77.11 & 30.21 & 35.49 \\
\hline 90 & 62.80 & 59.60 & 24.76 & 30.23 & 81.20 & 77.10 & 29.71 & 35.09 \\
\hline
\end{tabular}

Persamaan untuk menghitung panas yang dipindahkan dari beda temperatur air pendingin yaitu:

$\mathbf{Q}_{\text {out }}=\dot{\mathbf{m}}_{\mathrm{w}} \mathbf{c}_{\mathrm{pw}}\left(\mathbf{T}_{\text {out }}-\mathbf{T}_{\mathrm{in}}\right)$

dimana :

$\dot{\mathrm{m}}_{\mathrm{w}}$ : laju aliran air pendingin $(\mathrm{kg} / \mathrm{s})$

$\mathrm{c}_{\mathrm{pw}}$ : kalor jenis air $(\mathrm{J} / \mathrm{Kg} \mathrm{K})$

$\mathrm{T}_{\mathrm{in}}$ : temperatur air masuk $\left({ }^{\circ} \mathrm{C}\right)$

$\mathrm{T}_{\text {out }}$ : temperatur air keluar $\left({ }^{\circ} \mathrm{C}\right)$

Sebagai contoh perhitungan digunakan pipa kalor dengan sumbu fiber carbon sudut kemiringan $90^{\circ}$, perhitungan sudut yang lain dilanjutkan menggunakan program excel 2007. Hasil perhitungan ditunjukkan oleh Tabel 2

Data yang diketahui :

$\dot{\mathrm{m}}_{\mathrm{w}}: 6.00 \mathrm{E}-04(\mathrm{~kg} / \mathrm{s})$

$c_{p w}: 4200(\mathrm{~J} / \mathrm{kg} \mathrm{K})$ 
D $\quad$ : $9.53 \mathrm{E}-03(\mathrm{~m})$

A : $7.13 \mathrm{E}-05\left(\mathrm{~m}^{2}\right)$

$1 \quad: 0.27(\mathrm{~m})$

$\mathrm{T}_{\text {in }} \quad: 24.76\left({ }^{\circ} \mathrm{C}\right)$

$\mathrm{T}_{\text {out }}: 30.23\left({ }^{\circ} \mathrm{C}\right)$

$\overline{\mathrm{T}}_{\mathrm{c}} \quad: 59.60\left({ }^{\circ} \mathrm{C}\right)$

$\overline{\mathrm{T}}_{\mathrm{e}} \quad: 62.80\left({ }^{\circ} \mathrm{C}\right)$

Perpindahan panas $\left(\mathrm{Q}_{\text {out }}\right)$ :

$$
\begin{aligned}
\mathbf{Q}_{\text {out }} & =\dot{\mathbf{m}}_{\mathbf{w}} \mathbf{c}_{\mathbf{p w}}\left(\overline{\mathbf{T}}_{\text {out }}-\overline{\mathbf{T}}_{\text {in }}\right) \\
& =6.00 \mathrm{E}-04\left(\frac{\mathrm{kg}}{\mathrm{s}}\right) \times 4200\left(\frac{\mathrm{J}}{\mathrm{kg}} \mathrm{K}\right) \times \quad(30.23-24.76)\left({ }^{\circ} \mathrm{C}\right) \\
& =13.8(\mathrm{~W})
\end{aligned}
$$

Tabel 2 Laju perpindahan panas pipa kalor variasi sumbu terhadap sudut kemiringan

\begin{tabular}{|c|c|c|}
\hline \multirow{2}{*}{ Sudut } & \multicolumn{2}{|c|}{ Qout $_{\mathbf{~}}(\mathbf{W})$} \\
\cline { 2 - 3 } & Fiber Carbon & Stainless stell \\
\hline 0 & 13.2 & 12.3 \\
\hline 30 & 13.4 & 12.8 \\
\hline 45 & 13.5 & 13.1 \\
\hline 60 & 13.6 & 13.3 \\
\hline 90 & 13.8 & 13.6 \\
\hline
\end{tabular}

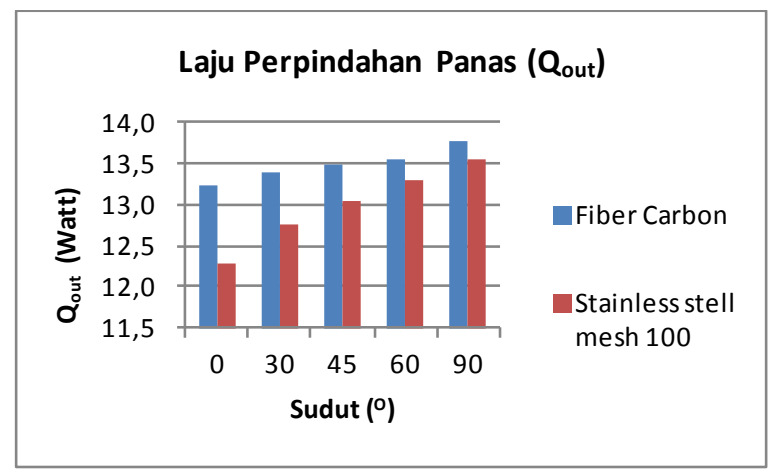

Gambar 7 Grafik Laju perpindahan panas pipa kalor dari variasi sumbu

Persamaan untuk menghitung koefisien perpindahan panas $(\mathrm{k})$, yaitu : 


$$
\begin{aligned}
\mathbf{k} & =\frac{\mathbf{Q}_{\text {out }} \mathbf{l}}{\mathbf{A}\left(\overline{\mathbf{T}}_{\mathbf{e}}-\overline{\mathbf{T}}_{\mathbf{c}}\right)} \\
& =\frac{7.51(\mathrm{~W}) \times 0.27(\mathrm{~m})}{7.13 \mathrm{E}-05\left(\mathrm{~m}^{2}\right) \times(62.80-59.60)(\mathrm{oC})} \\
& =16299.96(\mathrm{~W} / \mathrm{mK})
\end{aligned}
$$

Contoh perhitungan menggunakan pipa kalor dengan sumbu fiber carbon sudut kemiringan $90^{\circ}$, perhitungan sudut yang lain dilanjutkan menggunakan program excel 2007.

Hasil perhitungan ditunjukkan oleh Tabel 3.

Tabel 3 Konduktivitas perpindahan panas pipa kalor variasi sumbu terhadap sudut kemiringan

\begin{tabular}{|l|c|c|}
\hline \multirow{2}{*}{ Sudut } & \multicolumn{2}{|c|}{$\mathbf{k}$ (W/mK) } \\
\cline { 2 - 3 } & Fiber Carbon & Stainless stell \\
\hline 0 & 10167.64 & 8451.01 \\
\hline 30 & 12709.67 & 9675.97 \\
\hline 45 & 14560.98 & 11239.82 \\
\hline 60 & 15494.50 & 11711.78 \\
\hline 90 & 16299.96 & 12526.40 \\
\hline
\end{tabular}

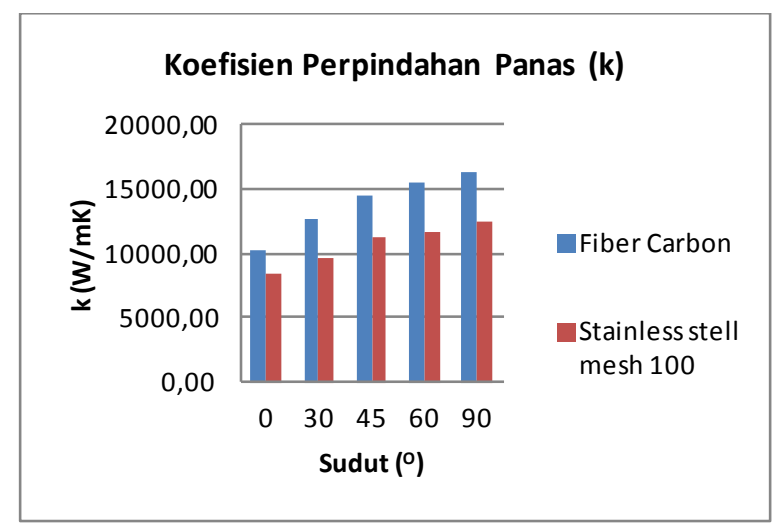

Gambar 8 Konduktivitas termal pipa kalor

\section{KESIMPULAN}

Perpindahan panas pipa kalor tertinggi terjadi pada pipa kalor dengan sumbu fiber carbon diikuti oleh pipa kalor sumbu stainless stell mesh 100 dan yang paling kecil adalah kecil dari pipa kalor dengan sumbu stainless stell mesh 100 dan. 


\section{DAFTAR PUSTAKA}

1. Dunn, P., and Reay, D A, (1982): Heat Pipes, Third Edition, Pergamon Press, Oxford United Kingdom.

2. Reay, David., Kew, Peter, (2006): Heat Pipes Theory, Design and Application, Fifth Edition, Elservier, United Kingdom

3. Chi, S.W., (1976), Heat Pipe Theory and Practice, Hemispere Publising Corporation, Washington.

4. Engineering Science Data Unit, 79012, (1980), Heat Pipes - performance of capillary - driven design.

5. F. Bagus Prayitno SP (1990), Pembuatan dan Komputerisasi Bangku Uji Pipa Kalor Dengan Studi Kasus Kaji Eksperimental Pipa Kalor Pada Daerah temperatur Menengah, ITB, Bandung

6. Sembiring, Tarlo, (2005), Kajian Peningkatan Perpindahan Panas dengan Pipa Kalor yang Beroperasi pada Temperatur Menengah, ITB, Bandung

7. Yoga, Nugroho Gama, (2005), Kaji Eksperimental Karateristik Pipa Kalor Untuk Berbagai Rasio Pengisian, Fluks Panas dan Kemiringan, Thesis ITB, Bandung

8. Zulfikar, (2006), Kaji Eksperimental Pipa kalor Dengan Berbagai Jenis Fluida Kerja, ITB, Bandung

9. Sutrisno, (2009), Kaji Eksperimental Pipa kalor Diaplikasikan Sebagai Pendingin CPU, ITB, Bandung

10. Incropera, Frank P, and De Witt, David P., (1990), Introduction to Heat Transfer, Second Edition, John Wiley \& Sons, New York. 